\title{
Isolated Myeloid Sarcoma of the Gastrointestinal Tract
}

\author{
Darko Antic ${ }^{1}$, Ivo Elezovic ${ }^{1}$, Andrija Bogdanovic ${ }^{1}$, Nada Suvajdzic Vukovic ${ }^{1}$, \\ Aleksandra Pavlovic ${ }^{2}$, Maja Perunicic Jovanovic ${ }^{1}$, Ljubomir Jakovic ${ }^{1}$ and Nada Kraguljac ${ }^{1}$
}

\begin{abstract}
Myeloid sarcoma (MS) is a rare disease that presents as an extramedullary tumor of myeloid cells. Most patients subsequently develop acute myelogenous leukemia (AML), and their prognosis is poor. Here, we report the case of a 28-year-old woman with a primary isolated myeloid sarcoma which originated in the gastrointestinal (GI) tract. Two months after intial presentation, bone marrow tests led to a diagnosis of AML. This case is noteworthy because GI tract infiltration with leukemic cells is very rare, and it is even more rare as an occurrence preceding the development of systemic leukemia.
\end{abstract}

Key words: gastrointestinal, myeloid sarcoma

(Inter Med 49: 853-856, 2010)

(DOI: 10.2169/internalmedicine.49.2874)

\section{Introduction}

Myeloid sarcoma (MS) is a solid tumor composed of immature myeloid cells (blasts); it may occurr as an isolated mass, or it may involve multiple organs. The condition was first described in 1811 by Burns (1), and in 1853, King realized that many of these tumors displayed a predominantly green colour, due to the presence of myeloperoxidase (MPO) in the tumorous tissue (2). The term granulocytic sarcoma to describe MS was first suggested by Rappaport in 1966 (3), then, in 2002, the World Health Organization adopted the use of the term myeloid sarcoma (4). Cases have been reported of MS in the lymph nodes, skin, periosteum, genital system, central nervous system, heart, and gastrointestinal (GI) tract (5-9).

\section{Case Report}

A 28-year-old woman presented with abdominal pains and jaundice and was hospitalized in a regional medical center. Laboratory analysis revealed a hemoglobin level of 118 $\mathrm{g} / \mathrm{L}$, white blood cell count of $5.5 \times 10^{9} / \mathrm{L}$, a normal differential count with platelets at $297 \times 10^{9} / \mathrm{L}$, total $/$ direct bilirubin $=$ $56 / 15.8 \mu \mathrm{mol} / \mathrm{L}$, alkaline phosphatase $=1,000 \mathrm{U} / \mathrm{L}, \mathrm{gGT}=268$ $\mathrm{U} / \mathrm{L}, \mathrm{AST}=118 \mathrm{U} / \mathrm{L}$, and ALT=337 U/L; HbsAg and anti$\mathrm{HCV}$ were negative. An ultrasound and MRI examination revealed gallbladder calculus, for which she underwent a cholecystectomy. During surgery an extreme thickening of the common bile duct was the only abnormality noted, and an ex tempore analysis of the common bile duct specimens did not confirm the presence of malignant cells.

During the post-operative period, the patient's liver function parameters deteriorated and she tested positive for blood in the stool. Esophagogastroduodenoscopy (EGDS) and rectoscopy indicated infiltrative changes to the stomach, duodenum and rectum. An initial pathohistological analysis without immunostains indicated that it was a MALT lymphoma. For the purpose of further hematology examinations, the patient was sent to our institution two months after the inital presentation of symptoms. At our institution, the initial pathohistological specimens were immediately re-examined. Analyses confirmed diffuse infiltration of the duodenal tissue by medium-sized neoplastic cells with dispersed chromatin and a variably basophilic cytoplasm. Immunostains revealed an intense reactivity to myeloperoxidase (MPO), CD 34, CD117 and CD43 (Fig. 1). At that time, blood tests revealed leukocytosis $\left(22.5 \times 10^{9} / \mathrm{L}\right)$ with $27 \%$ blasts and a hypercellular bone marrow aspirate. There were $71 \%$ blasts that stained intensely positive for myeloperoxidase, $12 \%$ mature granulocytes, 5\% eosinophils, $1 \%$ plasma cells, $7 \%$ monocytes, and $4 \%$ lymphocytes. Also, bone marrow biopsy analysis with additional immunohistochemistry (Fig. 2) coresponded with acute myelogenous leukemia (clear positivity

${ }^{1}$ Institute of Hematology, Clinical Center Serbia, Belgrade and ${ }^{2}$ Institute of Gastroenterology, Clinical Center Serbia, Belgrade Received for publication September 8, 2009; Accepted for publication January 7, 2010 Correspondence to Dr. Darko Antic, tweety@scnet.rs 


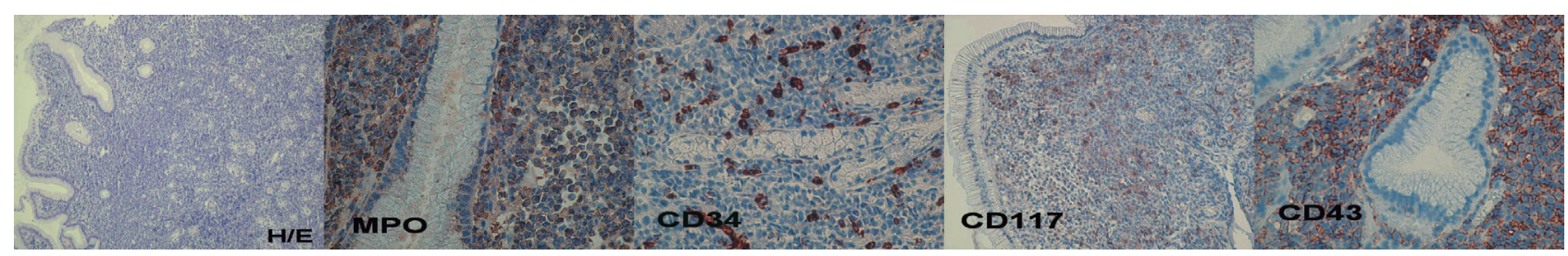

Figure 1. Leukemic infiltrates in lamina propria of the duodenum and numerous blasts with MPO, CD34, CD43, CD117 positivity were found. $\times 400$.

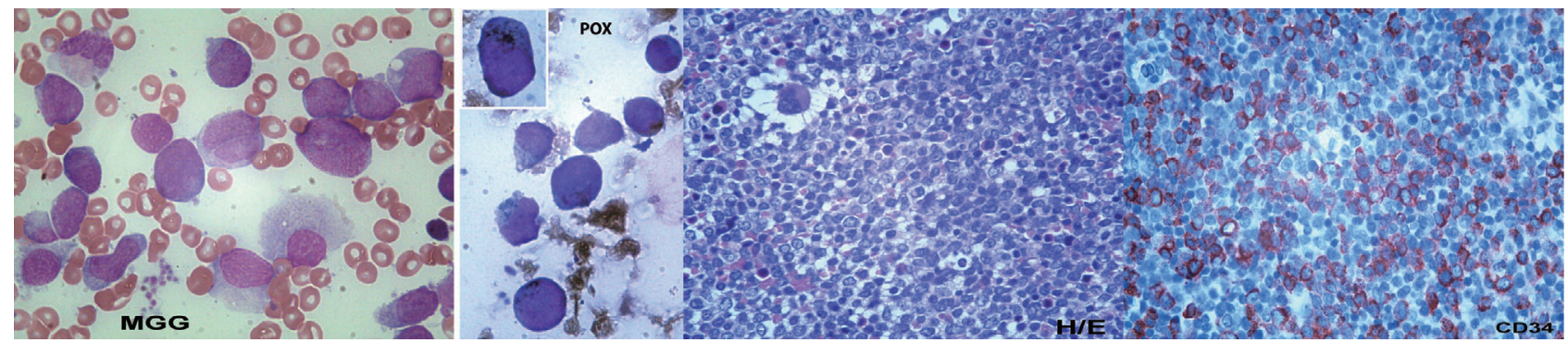

Figure 2. Bone marrow smears (MGG and POX) and biopsy analysis (Hematoxylin and Eosin staining and CD34) confirmed AML.

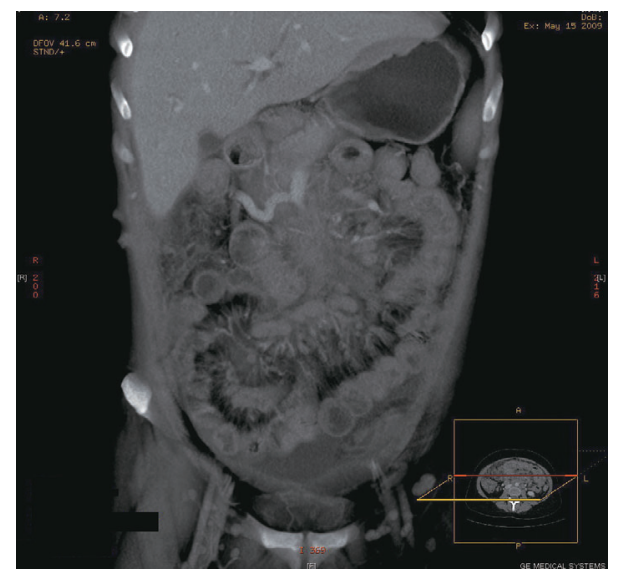

Figure 3. Significant thickening and edema of the entire small-intestine wall was found.

for CD34, MPO, CD117 and CD43). Flow cytometry performed on the bone marrow sample revealed two blast populations: the first population (42\% of cells) expressed HLA-DR, CD34, CD117, CD13, CD33, and MPO, while the second population (30\% of cells) expressed HLA-DR, CD34, CD117, CD13, CD33, MPO, CD11b, CD15, CD64, $\mathrm{CD} 14, \mathrm{CD} 4$, and CD2. Cytogenetic analysis revealed a normal 46, XX karyotype, and a diagnosis of acute myelogenous leukemia (AML, CD2+) was confirmed. Multi-slice computed tomography (MSCT) revealed significant thickening and edema of the entire small intestine wall (Fig. 3). The EGDS and colonoscopy were repeated, and they indicated that the stomach, duodenum, caecum, and colon had all been completely altered by a large number of polypoid infiltrative changes (Fig. 4). Pathohistological analyisis confirmed the diagnosis of myeloid sarcoma, however, the patient refused treatment.

Discussion

MS is likley underdiagnosed, and thus an accurrate prevalence rate for this disease is difficult to determine, however, it has been estimated that MS appears in 2/1,000,000 adults and $0.7 / 1,000,000$ children (10). MS may occur as an isolated tumor without bone marrow infiltration (4), or, it may present as a disseminated disease involving many organs. Unless treated, almost $90 \%$ of patients who do not demonstrate any further haematological disorders will develop AML within 10.5-11 months (11). Involvement of the GI tract is relatively rare, being reported in 4 of 61 (7\%) of tumors by Neiman et al (12). In our opinion, the present patient had an isolated myeloid sarcoma that progressed quickly to AML. In fact, although an initial bone marrow analysis was not performed, the patient was admitted to the hospital without any significant abnormalities in blood count.

The prognosis of isolated myeloid sarcoma largely depends on how early it is first diagnosed. Gastrointestinal MS is difficult and complicated to diagnose, since it may present with a wide spectrum of non-specific simptoms, including jaundice, chronic diarrhea, nausea, anorexia, and abdominal pain. In the absence of hematological disorders, 46-75\% of patients are initially diagnosed with conditions other than MS; most often, the misdiagnosis is $\operatorname{NHL}(13,14)$. During differential diagnosis, it is necessary to also consider poorly differentiated cancers and melanoma, and it children, neuroblastoma, rhabdomyosarcoma, Ewing sarcoma and medulloblastoma (15). Analysis of pathohistological specimens obtained by EGDS and/or colonoscopy must be carefully analyzed, and should involve an immunohistohemical analysis. If it is suspected that the tumor is of hematological origin, 


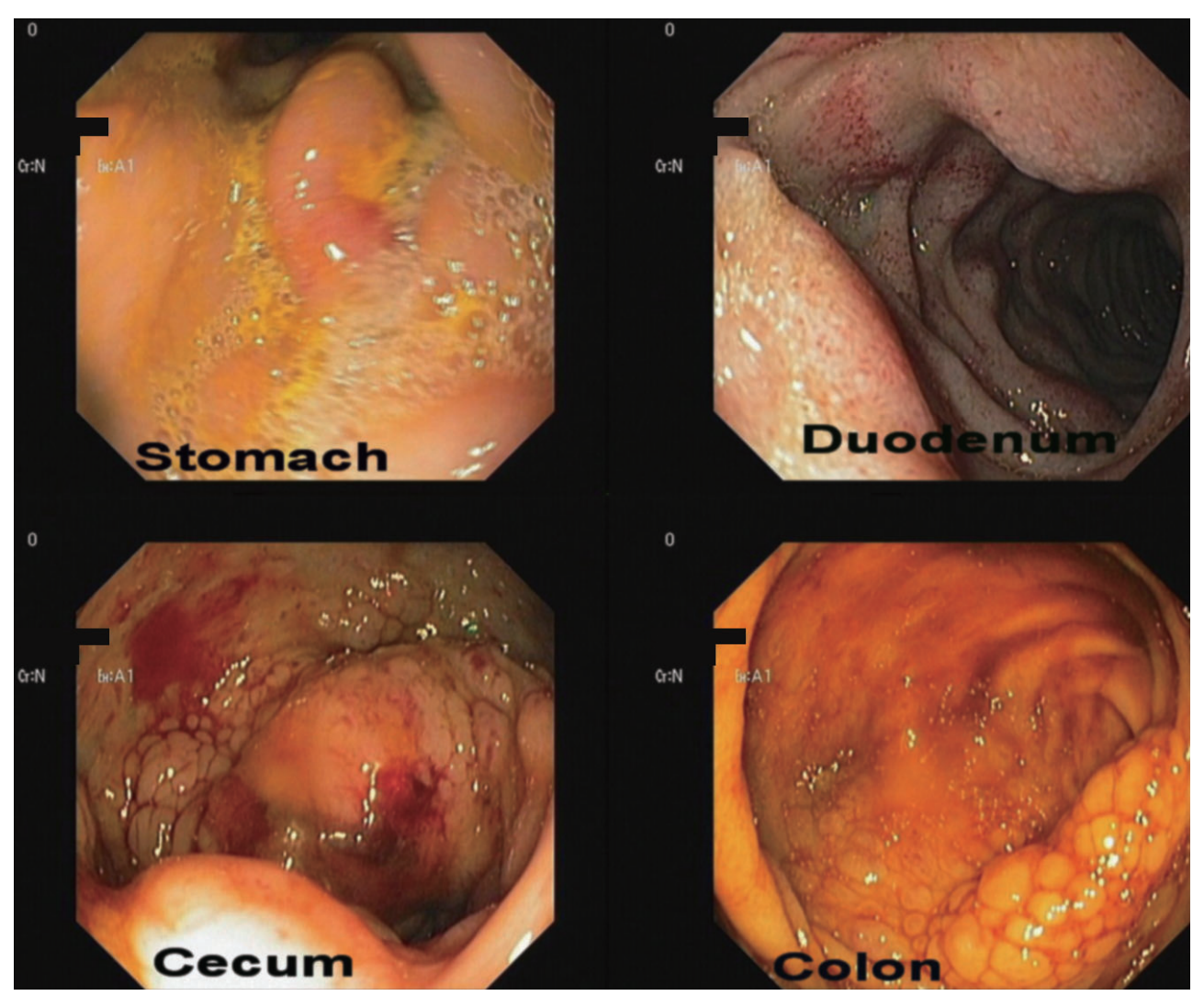

Figure 4. Numerous polypoid infiltrative changes in stomach, duodenum, cecum and colon were seen.

then an analyisis of myeloid markers is also nessessery. Since the myeloblasts in MS possess an antigen profile similar to the blasts and precursor cells in AML (16), myeloid infiltration can be assessed using immunohistochemical stains detecting MPO, CD 34, CD 117, lysosim, and chloracetate esterase. An optimal therapy has not yet been clearly defined, in part because of the varied clinical presentations. Chemotherapy, transplantation of hematopoiesis stem cells, radiotherapy, surgical resection, or a combination of these approaches are used on a case by case basis (17-24).

Infiltration of the GI tract with leukemic cells is very rare and the prognosis for these patients is poor; they are at particular risk of complications such as perforation, bleeding, necrosis, obstruction, and intussusceptions (25). If the tumor is localized, resection of the mass can be considered, but in the case of disseminated disease, treatment should be systemic.

\section{References}

1. Burns A. Observation of Surgical Anatomy, Head and Neck. Thomas Royce and Co., Edinburgh, 1811: 364-366.

2. King A. A case of chloroma. Monthly J med 17: 97, 1853.

3. Rappaport H. Tumours of the hematopoietic system. In: Atlas of Tumor Pathology, Section III, Fascicle 8. Armed Forces Institute of Pathology, Washington, DC, 1966: 241-243.

4. Brunning RD, Matutes E, Flandrin G, et al. Acute myeloid leukaemia not otherwise categorized. In: Pathology and Genetics of Tumours of Haepatopoetic and Lymphoid Tissues. Jaffe ES, Harris NL, Stein H, Vardiman JW, Eds. IARC, Lyon, 2001: 104-105.

5. Paydas S, Zorludemir S, Ergin M. Granulocytic sarcoma: 32 cases and review of the literature. Leuk Lymphoma 47: 2527-2541, 2006.

6. Antic D, Verstovsek S, Elezovic I, et al. Spinal epidural granulocytic sarcoma in non-leukemic patient. Int J Hematol 89: 95-97, 2009.

7. Antic D, Vuckovic M, Elezovic I. Right atrial myeloid sarcoma causing superior vena cava syndrome. Br J Haematol 141: 134, 2008.
8. Derenzini E, Paolini S, Martinelli G, et al. Extramedullary myeloid tumour of the stomach and duodenum presenting without acute myeloblastic leukaemia: a diagnostic and therapeutic challenge. Leuk Lymphoma 49: 159-162, 2008.

9. Tummala M, Thomas L, Gocke C, et al. Unusual leukaemia presentations. Case 2. Granulocytic sarcoma of the colon. J Clin Oncol 23: 5840-5841, 2005.

10. Breccia M, Mandelli F, Petti MC, et al. Clinico-pathological characteristics of myeloid sarcoma at diagnosis and during follow-up: report of 12 cases from a single institution. Leuk Res 28: 11651169, 2004.

11. Hutchinson RE, Kurec AS, Davey FR. Granulocytic sarcoma. Clin Lab Med 10: 889-901, 1990.

12. Neiman RS, Barcos M, Berard C, et al. Granulocytic sarcoma: A clinicopathologic study of 61 biopsied cases. Cancer 48: 14261437, 1981.

13. Meis JM, Butler JJ, Osborne BM, Manning JT. Granulocytic sarcoma in nonleukemic patients. Cancer 58: 2697-2709, 1986.

14. Byrd JC, Edenfield WJ, Shields DJ, Dawson NA. Extramedullary 
myeloid cell tumours in acute non-lymphocytic leukaemia: A Clinical Review. J Clin Oncol 13: 1800-1816, 1995.

15. Alexiev BA, Wang W, Ning Y, et al. Myeloid sarcomas: a histologic, immunohistochemical, and cytogenetic study. Diagn Pathol 2: 42, 2007.

16. Audouin J, Comperat E, Le Tourneau A, et al. Myeloid sarcoma: clinical and morphologic criteria useful for diagnosis. Int J Surg Pathol 11: 271-282, 2003.

17. Sevinc A, Buyukberber S, Camci C, et al. Granulocytic sarcoma of the colon and leukemic infiltration of the liver in a patient presenting with hematochezia and jaundice. Digestion 69: 262-265, 2004.

18. Evans C, Rosenfeld CS, Winkelstein A, Shadduckc RK, Pataki KI, Oldham F. Perforation of an unsuspected cecal granulocytic sarcoma during therapy with granulocyte-macrophage colonystimulating factor. N Engl J Med 322: 337-338, 1990.

19. Makni S, Bahri I, Ayadi L, Mseddi A, Bouaziz M, Jlidi R. Colonic granulocytic sarcoma: A case report. Ann Chir 127: 480-483, 2002.
20. Kitagawa Y, Sameshima Y, Shiozaki H, et al. Isolated granulocytic sarcoma of the small intestine successfully treated with chemotherapy and bone marrow transplantation. Int J Hematol 87: 410413, 2008.

21. Choi EK, Ha HK, Park SH, et al. Granulocytic sarcoma of bowel: CT findings. Radiology 243: 752-759, 2007.

22. Yamauchi K, Yasuda M. Comparison in treatments of nonleukemic granulocytic sarcoma: report of two cases and a review of 72 cases in the literature. Cancer 94: 1739-1746, 2002.

23. Tsimberidou AM, Kantarjian HM, Wen S, et al. Myeloid sarcoma is associated with superior event-free survival and overall survival compared with acute myeloid leukaemia. Cancer 113: 1370-1378, 2008.

24. Pileri SA, Ascani S, Cox MC, et al. Myeloid sarcoma: clinicopathologic, phenotypic and cytogenetic analysis of 92 adult patients. Leukaemia 21: 340-350, 2007.

25. Chevallier P, Mohty M, Lioure B, et al. Allogeneic hematopoietic stem-cell transplantation for myeloid sarcoma: a retrospective study from the SFGM-TC. J Clin Oncol 26: 4940-4943, 2008.

(C) 2010 The Japanese Society of Internal Medicine http://www.naika.or.jp/imindex.html 